\title{
Fundamentos biológicos para a educação especial: anormalidades da formação cerebral e os transtornos de desenvolvimento neural
}

\section{Biological foudations for especial education: brain formation abnormalities and neural development disorders}

\author{
Umberto Euzebio $^{1 *}$, Júlio Fernandes Leite ${ }^{1}$
}

\begin{abstract}
RESUMO
Transtornos do desenvolvimento neural constituem um grupo bastante diverso de problemas identificáveis clinicamente, decorrentes de perturbações do desenvolvimento neurológico, manifestam-se desde a infância, são persistentes, geram algum grau de limitação seja na capacidade de aprendizagem, na comunicação, ou na interação social, o que produz reflexos na vida escolar, laboral ou outras áreas da vida. Os principais transtornos são: o transtorno do espectro autista (autismo), a deficiência intelectual (retardo mental ou deficiência mental), o transtorno do déficit de atenção e hiperatividade (TDAH), a epilepsia dos transtornos do desenvolvimento, a dislexia do desenvolvimento, a discalculia do desenvolvimento, a gagueira do desenvolvimento e a paralisia cerebral. Os transtornos do desenvolvimento neural podem ter diversas causas, genéticas e não genéticas (ambientais), e muitas vezes ambas contribuem para a ocorrência do transtorno. O objetivo deste trabalho é compreender os mecanismos envolvidos na origem dos transtornos de desenvolvimento neural durante a formação cerebral a partir de trabalhos da base de dados do índice Medline como contribuição para a área da Saúde e da Educação Especial.
\end{abstract}

Palavras-chave: Autismo; TDAH; Dislexia; Discalculia; Paralisia cerebral.

\begin{abstract}
Neurodevelopmental disorders are a very diverse group of clinically identifiable disorders that result from derangement of neural development, they are persistent and manifest from childhood, even if they are only recognized later, and generate some degree of limitation in the learning capacity, communication, or social interaction, which produces reflexes in school, work or other areas of life. The main neurodevelopmental disorders are autism spectrum disorder (autism), intellectual disability (mental retardation or mental disability), attention deficit hyperactivity disorder (ADHD), developmental epilepsy, developmental dyslexia, developmental dyscalculia, developmental stuttering and cerebral palsy. Neurodevelopmental disorders may have several causes, genetic and non-genetic (environmental), and often both act simultaneously. The aim of this work is to understand the mechanisms involved in the origin of neural development disorders during brain formation based on words from the Medline index database.
\end{abstract}

Keywords: Autism; ADAHD; Dyslexia; Dyscalculia; Cerebral Palsy.

\footnotetext{
${ }^{1}$ Universidade de Brasília.

*E-mail: umbertoeuz@gmail.com
} 


\section{INTRODUÇÃO}

A formação do Sistema nervosa inicia a partir do processo de neurulação, sendo o primeiro a iniciar a formação e praticamente o ultimo a terminar.

A estrutura cérebro espinhal tem origem no ectoblasto neural que sobre ação indutora neuralizante do tecido notocordal que irá modificar o seu epitélio cúbico simples para células altas contituindo-se assom em epitélio cilíndrico simples para formar a placa neural.

Com a invaginação da porção central placa neural ocorre o levantamento das laterais e com isso a formação do sulco e das cristas neurais e posteriormente a goteira neural. As cristas neurais, constituem-se nas bordas do sulco neural e mantem-se lateralmente ligadas ao ectoblasto cutâneo.

O fechamento do tubo neural ocorre do centro para as extremidades formando um tubo cujas extremidades são os neuróporos anterior e posterior que permite a circulação do líquido amniótico até que que se fecha totalmente após a formação das células que constituem os plexos coroides que irão secretar o líquor.

A porção anterior do tubo neural sofre ação indutora neutralizante provocando alterações profundas em toda a sua estrutura que irá atingir o seu ápice com a formação das vesículas cerebrais. Concomitante a esse processo o embrião sofre dobramentos longitudinal e transversal adquirindo formato corporal cilíndrico, tomando forma anatômica semelhante à do feto e do adulto. Nessa etapa as vesículas cerebrais também sofrem uma série de dobramentos e reposicionando-se para formar o telencéfalo que por sua vez origina os hemisférios cerebrais, primeiro e segundo ventrículos e os lobos olfativos. O diencéfalo se transforma nas estruturas do epitálamo e pineal, tálamo, hipotálamo, vesículas ópticas, neurohipófise e uma porção do terceiro ventrículo. A partir do mesencéfalo surgem parte do terceiro e quarto ventrículo, pedúnculo e aqueduto cerebral e os lobos ópticos. O metencéfalo irá formar a ponte, o cerebelo e as vesículas auditivas enquanto que o mielencéfalo, o bulbo e o restante do quarto ventrículo.

As alterações no desenvolvimento cerebral são de diferentes naturezas e surgem no momento em que estas estruturas estão em formação, porém não irão constituir apenas em alterações morfológicas, mas também de natureza diversa cujo resultado culmina em respostas comportamentais de amplo espectro que trataremos como transtornos do desenvolvimento neural. 
Nosso propósito neste trabalho é estudar esses transtornos, que constituem um grupo bastante diverso de problemas identificáveis clinicamente e que decorrem de perturbações do desenvolvimento neurológico. Segundo Segundo Gilbert e Hy (2017), Haberstroh e Schulte-Körne (2019), Choo, Smith e Li (2020), Thakran et al (2020), Hallman-Cooper e Cabero (2021), Lee; Cacella e Marwaha (2021), Magnus et al (2021) e Remien e Marwaha (2021), os principais transtornos do desenvolvimento neural são: transtorno do espectro autista (autismo), deficiência intelectual (retardo mental ou deficiência mental), transtorno do déficit de atenção e hiperatividade (TDAH), epilepsia dos transtornos do desenvolvimento, dislexia do desenvolvimento, discalculia do desenvolvimento, gagueira do desenvolvimento e paralisia cerebral.

Os transtornos do desenvolvimento neural podem ter diversas causas genéticas e não genéticas (ambientais), e muitas vezes ambas contribuem para a ocorrência do transtorno. Quando há causa genética identificada, esta pode ser uma mutação em um único gene (causa monogênica), ou, mais frequentemente, um conjunto de diversos genes que combinados num mesmo indivíduo produzem as características do transtorno (causa poligênica). Os fatores não genéticos, ou ambientais (neste caso o termo ambiental diz respeito ao ambiente do ser em formação, seja no período embrionário, fetal ou perinatal), são infecções, condições maternas (consumo de álcool ou drogas psicoativas e medicamentos, exposição a poluentes, etc.) e complicações do parto (GILBERT; HY, 2017; HABERSTROH; SCHULTE-KÖRNE, 2019; CHOO; SMITH; LI, 2020; THAKRAN et al, 2020; HALLMAN-COOPER; CABERO, 2021; LEE; CACELLA; MARWAHA, 2021; MAGNUS et al, 2021; REMIEN; MARWAHA, 2021).

Independentemente do tipo e suas causas, os transtornos do desenvolvimento neural têm características que se manifestam desde a infância, mesmo que sejam reconhecidos somente mais tarde, são persistentes, geram algum grau de limitação seja na capacidade de aprendizagem, na comunicação, ou na interação social, limitação essa que produz reflexos na vida escolar, laboral ou outras áreas da vida. Os transtornos do desenvolvimento neural são comuns em todas as sociedades, classes sociais e etnias, e para vários deles não há tratamento específico, eficaz ou satisfatório. Com muita frequência, as famílias de crianças com transtornos do desenvolvimento neurológico sentem que, apesar de todo o amor e aceitação, ter um filho com algum desses transtornos acaba por afetar seus relacionamentos familiares, a qualidade de vida dos irmãos, a economia familiar (quando o problema é suficientemente grave para fazer com que a 
pessoa afetada seja dependente de outros e incapaz de exercer atividades produtivas), e tudo isso leva ao sofrimento dos pais, especialmente os que vivem em condições econômicas menos privilegiadas, com menor possibilidade de acesso a serviços de apoio que permitam a liberação de outras pessoas da família para o exercício pleno de atividades econômicas necessárias à subsistência da família (ARORA et al, 2018; MINHA et al, 2020; OLUSANYA et al, 2020)

Portanto, é fundamental a compreensão dos transtornos do desenvolvimento neurológico e seus mecanismos fisiopatogênicos para elaborar novas e mais eficazes estratégias terapêuticas.

O objetivo deste trabalho é compreender os mecanismos envolvidos na origem dos transtornos de desenvolvimento neural durante a formação cerebral.

\section{METODOLOGIA}

Como metodologia, optamos pela revisão bibliográfica sobre o assunto com maior concentração em publicações dos últimos cinco anos. Sendo assim, buscamos textos de revisão sobre com as palavras-chave transtorno do espectro autista/autismo, deficiência intelectual/retardo mental/deficiência mental, transtorno do déficit de atenção e hiperatividade (TDAH), epilepsia do desenvolvimento, dislexia do desenvolvimento, discalculia do desenvolvimento, gagueira do desenvolvimento e paralisia cerebral, publicados na base de dados do índice Medline. Buscando maior compreensão dos múltiplos fatores envolvidos nos transtornos do desenvolvimento, fizemos outras buscas na base de dados do índice Medline cruzando palavras-chave neurogênese com cada transtorno no desenvolvimento.

\section{DESENVOLVIMENTO CEREBRAL}

O desenvolvimento neural do cérebro envolve os seguintes processos: a neruogênse com migração e proliferação de células precursoras de neurônios, e diferenciação de neurônios a partir de células-tronco; crescimento neural com prolongamento dos axônios e arborização de dendritos e a formação de redes com formação e remodelação de sinapses. (PAN; WU; YUAN, 2019). 


\section{NEUROGÊNESE}

Os neurônios se originam a partir de células bem mais simples com estrutura arredondada, que são células-tronco localizadas em determinadas áreas do embrião. Essas células-tronco neurais vão proliferando e migrando dentro do tecido embrionário em formação, tecido este que ainda não tem as características do órgão definitivo, e assim vão dando origem ao futuro cérebro. A migração neuronal é um evento fundamental no desenvolvimento dos circuitos cerebrais, e ocorre principalmente nos seis primeiros meses do período gestacional. Depois de sua produção em zonas germinativas do embrião (zona ventricular e subventricular externa), que são ricas em células-tronco neurais, a maioria dos neurônios jovens faz uma migração radial (como a partir do centro de uma esfera em direção à sua superfície) para determinadas regiões do cérebro ainda em formação, principalmente para o neocórtex. O neocórtex, "córtex mais recente", é a denominação que recebe a região do cérebro que, no processo evolutivo, se desenvolveu mais recentemente e é encontrada em todos os mamíferos, embora a proporção de neocórtex em relação à massa total do cérebro seja variável entre as diferentes espécies (em humanos alcança 80\% da massa total do cérebro). Essa área constitui a "capa" neural relativamente fina (com espessura de $1 \mathrm{~mm}$ em camundongos, a 2,5mm em humanos) que recobre os lobos pré-frontais e frontais, e é subdividida em 6 subcamadas principais (denominadas lâminas corticais), cujos neurônios possuem axônios que alcançam outras estruturas cerebrais fora do neocórtex e por isso são denominados neurônios de projeção. O neocórtex é a porção anatomicamente mais complexa do córtex (camada superficial do cérebro, composta de substância cinzenta), e constitui o substrato anatômico de funções cerebrais como cognição, linguagem, criatividade e consciência. O desenvolvimento do neocórtex requer posicionamento e conexão precisos de bilhões de neurônios, e acreditase que essa organização extraordinariamente complexa seja geneticamente codificada e posteriormente refinada por processos dependentes da atividade desses neurônios em decorrência de estímulos externos. Em humanos, o neocórtex, assim como toda a superfície cerebral, ainda é liso na $20^{a}$ semana de gestação, e a partir daí se expande através da formação de sulcos e dobras (denominados giros) até o nascimento, o que promove aumento de 7,5 vezes na área da superfície cerebral (HEUER; TORO, 2019).

Os neurônios de projeção migram radialmente (do centro para a superfície da estrutura arredondada que dará origem ao cérebro) para formar as seis subcamadas do neocórtex, processo denominado laminação cortical, de modo que os neurônios formados mais 
tarde durante a neurogênese atravessam as camadas da superfície neocortical já formadas, e se posicionam acima dos neurônios que se formaram antes. Inicialmente, os neurônios migram através de locomoção celular (movimentos ativos da célula), mas à medida que seguem seu caminho em direção ao neocórtex, eles aderem e migram ao longo da glia (células de sustentação), como se encostassem numa corda-guia de uma trilha, o que ajuda no direcionamento de sua migração (durante o desenvolvimento, até $90 \%$ dos neurônios humanos migram guiados pela glia). À medida que se movem ao longo da glia, os neurônios em formação se transformam - de células precursoras arredondadas, adotam uma morfologia bipolar (corpo central e dois prolongamentos principais, a saber, um axônio e um dendrito com arborização terminal) - e se desprendem da glia ao atingir sua localização final. Além disso, os neurônios localizados em diferentes subcamadas neocorticais, mas que foram gerados a partir da mesma célula mãe precursora, alinhamse em estruturas colunares altamente conectadas, provavelmente constituindo uma unidade funcional no cérebro. Em alguns casos de transtorno do espectro autista ocorrem regiões de posicionamento laminar anormal dos neurônios corticais (distribuição alterada de neurônios nas subcamadas corticais). Tanto o desenvolvimento adequado da laminação (formação das subcamadas) quanto o número de neurônios corticais dependem da proliferação temporalmente controlada de células precursoras neurais. Os neurônios neocorticais de projeção produzem como neurotransmissor o glutamato, o principal neurotransmissor excitatório, e por isso são ditos neurônios glutamatérgicos (GILBERT; HY, 2017).

Os interneurônios corticais, são os que fazem a conexão entre neurônos das várias subcamadas do neocórtex, são predominantemente inibitórios dos circuitos em que estão inseridos, e funcionam por meio da liberação do neurotransmissor GABA (ácido $\gamma$ aminobutírico), principal neurotransmissor inibitório da atividade elétrica dos neurônios, chamados de GABAérgicos. Na formação do cérebro, ao contrário dos neurônios de projeção que formam as subcamadas do neocórtex, que migram radialmente, os interneurônios migram de modo tangencial à superfície do neocórtex (como se a partir do polo inferior de um globo caminhassem pela superfície deste, para alcançar o polo superior), ou seja, migram pela superfície ao longo das subcamadas corticais em formação (GILBERT; HY, 2017).

A migração neuronal no cérebro em desenvolvimento é altamente sensível a vários fatores nocivos, sejam físicos, químicos ou biológicos, assim como mutações 
genéticas. Defeitos nas engrenagens moleculares da migração neuronal levam a erros da localização dos neurônios afetados, ou heterotopia neuronal, que é a presença de determinado tipo de neurônio numa parte do cérebro onde normalmente eles não são encontrados. Esses erros de localização geram malformações que interferem no funcionamento de vários circuitos cerebrais e são considerados elementos causais importantes em vários transtornos do desenvolvimento neural, como a epilepsia, deficiência intelectual, dislexia, e transtorno do espectro autista (GILBERT; HY, 2017).

\section{CRESCIMENTO NEURONAL}

Os axônios navegam através de um ambiente complexo no embrião em direção aos seus alvos, que podem estar bem distantes do seu corpo celular. Espécies com simetria bilateral, incluindo os humanos, possuem um eixo da linha média, que é uma estrutura importante para a conexão adequada do sistema nervoso. Essa característica se torna ainda mais importante nos vertebrados, devido à complexidade do sistema nervoso onde neurônios em formação precisam decidir se cruzam ou não a linha média, ou se enviam seus axônios para uma direção ventral (para a parte da frente do corpo) ou dorsal (parte de trás do corpo). Atualmente sabe-se que os axônios dos neurônios que se diferenciam mais tardiamente formam fascículos (se juntam em feixes) com os axônios dos neurônios que se diferenciam mais precocemente, ou simplesmente seguem o rastro destes. Já os neurônios que se formam mais precocemente precisam navegar por um ambiente que é composto por um mar de células indiferenciadas arredondadas (células precursoras embrionárias, que ainda não se transformaram em neurônios ou em qualquer outro tipo de célula típica do indivíduo adulto) (NIFTULLAYEV; LAMARCHE-VANE, 2019).

Já foram identificadas diversas proteínas que funcionam como direcionadores moleculares dos neurônios (netrinas, slits, semaforinas, efrinas), assim como seus receptores, que participam do controle da montagem e desmontagem do citoesqueleto (finas estruturas celulares que funcionam como vigas de sustentação de paredes, e que determinam o formato e mudança de formato das células). Através de seus efeitos na montagem e desmontagem do citoesqueleto, essas proteínas determinam a orientação dos axônios. Outros sistemas de sinalização também contribuem para esse processo, como as proteínas Wnt, Shh e TGF-Beta (NIFTULLAYEV; LAMARCHE-VANE, 2019).

Os dendritos são as principais estruturas neuronais que recebem sinais de outros neurônios e células da glia. Eles contêm prolongamentos dendríticos, que são saliências 
microscópicas na membrana celular dos dendritos e que recebem as sinapses excitatórias no cérebro. Os espinhos dendríticos contêm neurotransmissores, seus respectivos receptores, moléculas sinalizadoras internas, canais iônicos e outras proteínas que participam da transmissão sináptica. Dendritos de um único neurônio podem conter centenas a milhares de espinhos, e cada espinho maduro tipicamente tem uma única sinapse localizada na sua cabeça (MARTíNEZ-CERDEÑO, 2017).

Uma vez que os neurônios alcançam seu destino nas camadas corticais, as características básicas dos dendritos dos neurônios corticais começam a se desenvolver no córtex humano entre 17 e 25 semanas de gestação, com crescimento e ramificação substanciais dos dendritos para formar a arborização dendrítica típica dos diversos tipos de neurônio maduros do córtex. O crescimento de axônios entre 26 e 34 semanas de gestação coincide com intensa diferenciação dendrítica e o aparecimento de espinhos nos dendritos. Nos seres humanos, os neurônios crescem e continuam a elaborar sua arborização dendrítica, seus axônios e formar novas conexões sinápticas até os três anos de idade. Mas durante o desenvolvimento da árvore dendrítica, as sinapses são produzidas em números que excedem os presentes no cérebro adulto. A depender da sua atividade, as sinapses passam por um processo de estabilização, ou podem ser seletivamente retraídas e eliminadas (poda sináptica, ou poda dendrítica). Essa possibilidade de modificação da árvore dendrítica é importante para a modulação da atividade dos circuitos neuronais, e para a plasticidade neural. A poda sináptica ocorre de modo mais acentuado na puberdade, mas continua além da adolescência e ao longo da terceira década de vida (MARTÍNEZ-CERDEÑO, 2017).

No sistema nervoso adulto, a árvore dendrítica é menos sujeita a modificações. Já os espinhos dendríticos sofrem rotações constantes e modificações morfológicas que dependem de estímulos, ambiente e localização, modificações essas que são essenciais para a modulação da atividade sináptica, principalmente na vida adulta. A morfologia dos espinhos dendríticos, assim como seu número e densidade, são fatores cruciais para determinar a força e a estabilidade da transmissão sináptica. Funções como aprendizado, memória, comportamento e coordenação motora requerem modificações no espinho dendrítico para regular a transmissão sináptica. O processo de desenvolvimento da árvore dendrítica, assim como a sua estabilização, é regulado por programas genéticos e uma ampla variedade de sinais extracelulares. Portanto, uma grande contribuição para o 
aumento do tamanho do cérebro pós-natal provavelmente resulta do aumento do crescimento dendrítico (MARTÍNEZ-CERDEÑO, 2017).

\section{FORMAÇÃO DAS REDES NEURAIS}

O cérebro humano contém cerca de 86 bilhões de neurônios fazendo trilhões de conexões. Uma das etapas fundamentais durante o desenvolvimento do sistema nervoso é a formação de conexões adequadas entre neurônios e seus alvos celulares - o processo de conexão neural ou formação das redes neurais. A formação bem sucedida de conexões neurais é crucial para o desenvolvimento de todas as funções comportamentais. Sinapses são estruturas altamente especializadas necessárias para a transmissão do sinal nas redes neuronais, constituindo os locais de contato funcionais entre os neurônios. Uma sinapse é composta pelo terminal axonal (extremidade final do axônio, que envia o sinal para o neurônio alvo), a pré sinapse (ponta da extremidade do axônio), uma fenda sináptica (espaço reduzido onde a extremidade do axônio mais se aproxima do dendrito do neurônio alvo) que contém proteínas de adesão e matriz extracelular, e a pós sinapse, membrana do dendrito de um neurônio alvo (GILBERT; HY, 2017).

A pré sinapse contém mitocôndrias e é caracterizada por um conjunto de vesículas sinápticas preenchidas com neurotransmissores. Os potenciais de ação (impulsos elétricos) que chegam ao terminal axonal determinam entrada de cálcio no terminal axonal, o que faz com que as vesículas sinápticas se fundam com regiões especializadas da membrana plasmática (a parede externa do neurônio) para liberar seu conteúdo na fenda sináptica. Um acoplamento preciso entre o potencial de ação e a liberação do neurotransmissor é crucial para a transmissão adequada do sinal ao neurônio póssináptico. A pós sinapse (no dendrito do neurônio alvo) é caracterizada pela presença de receptores na superfície do dendrito, onde se ligam os neurotransmissores liberados a partir da pré sinapse, e assim os receptores são ativados, permitindo a passagem de íons e/ou iniciando cascatas de sinalização intracelulares (ativação de diversas proteínas e enzimas) que modulam a atividade do neurônio pós-sináptico (o neurônio alvo) (GILBERT; HY, 2017).

Os receptores de neurotransmissores estão agrupados em uma região chamada densidade pós sináptica na sinapse. As sinapses são classificadas como excitatórias ou inibitórias, dependendo se usam glutamato (o principal neurotransmissor excitatório) ou GABA (o principal neurotransmissor inibitório) respectivamente. Além disso, a formação 
e a estrutura de sinapses excitatórias e inibitórias são diferentes. As sinapses excitatórias são feitas em espinhos dendríticos, enquanto as sinapses inibitórias são formadas diretamente no caule do dendrito. Além disso, as sinapses excitatórias e inibitórias possuem perfis distintos de proteínas especializadas para cada sinapse, e moléculas de sinalização apropriadas (GILBERT; HY, 2017).

Quando aprendemos novas informações ou consolidamos informações antigas ou planejamos o futuro, nosso cérebro está gerando novas conexões neurais e regenerando velhas conexões. A plasticidade neural descreve a versatilidade da conectividade e dos circuitos neurais como adaptação a mudanças nas condições do corpo e do ambiente. Assim, a plasticidade é um exercício que o cérebro faz naturalmente, para se adaptar a novas situações, se ajustar e mudar de acordo com as demandas da situação, é o combustível para a resiliência, a arte de se adaptar com inteligência para sobreviver. A plasticidade sináptica pode ser efêmera (de curto prazo) ou duradoura (de longo prazo). Os mecanismos envolvidos na plasticidade sináptica de curto prazo e o impacto desta para o comportamento e funções cognitivas ainda precisam ser compreendidos. A plasticidade de longo prazo por ser de dois tipos: a potenciação de longo prazo, que é uma facilitação da transmissão do sinal entre dois neurônios, decorrente de atividade sináptica de alta frequência, e está associada a aumento dos espinhos dendríticos; ou a depressão de longo prazo, que é a inibição da transmissão do sinal entre dois neurônios, decorrente de atividade sináptica de alta frequência, e está associada a encolhimento dos espinhos dendríticos (GILBERT; HY, 2017; JACKMAN; REGEHR, 2017).

Fatores neurotróficos, ou neurotrofinas, são proteínas produzidas por neurônios no sistema nervoso central e que têm um papel crucial na sobrevivência dos neurônios e na neurogênese durante o período fetal e na infância. $O$ fator neurotrófico derivado do cérebro (BDNF, brain derived neurotrophic factor) é a neurotrofina mais estudada e melhor caracterizada do sistema nervoso central. O cérebro adulto continua produzindo BDNF, e nessa fase da vida o BDNF desempenha diversos papéis importantes, tais como nos apresenta Niftullayev e Lamarche-Vane (2019) e Pan, Wu e Yuan (2019): sobrevivência dos neurônios; formação e crescimento de novos neurônios a partir de células tronco (neurogênese no cérebro adulto); formação e estabilização de sinapses; regulação da transmissão sináptica excitatória e inibitória; aumento do número, tamanho e complexidade dos espinhos dendríticos, levando à estabilização das sinapses e potenciação de longo prazo, e assim contribui para a formação de memória. 


\section{TRANSTORNOS DO DESENVOLVIMENTO NEURAL}

O termo transtorno do espectro autista descreve um conjunto de transtornos do desenvolvimento neural que são persistentes e incapacitantes, clinicamente evidentes desde a primeira infância, mesmo que esses sintomas não sejam reconhecidos até mais tarde, e caracterizados por déficits na comunicação social e na interação social, por padrões repetitivos de comportamento, e limitação de interesses ou atividades, o que de algum modo compromete a capacidade da pessoa funcionar adequadamente na escola, no trabalho e em outras áreas da vida. O autismo é dito como um transtorno do "espectro" porque há uma grande variedade no tipo e na gravidade dos sintomas que as pessoas afetadas apresentam. A prevalência de transtorno do espectro autista é de cerca de $2 \%$ da população com a proporção média de homens 4 a 5 vezes maior do que em mulheres. Cerca de 50\% das crianças com transtorno do espectro autista também têm deficiência intelectual. Entre pessoas adultas com diagnóstico de transtornos psiquiátricos, a prevalência de transtorno do espectro autista varia de 2,4 a 9,9\%. O autismo pode ocorrer como um transtorno puro, sem outras alterações físicas congênitas, caso em que é chamado de autismo essencial, ou as características do autismo podem ocorrer com outras manifestações, malformações ou anomalias congênitas, o que se denomina autismo sindrômico. O autismo essencial ocorre em aproximadamente $75 \%$ dos casos de transtorno do espectro autista. Quando há uma causa genética, o que ocorre em apenas cerca de $15 \%$ dos casos de autismo essencial, esta geralmente é poligênica (vários genes envolvidos), o risco de ocorrência em irmãos é de $35 \%$, e cerca de $20 \%$ dos casos têm histórico familiar positivo para transtorno do espectro autista. Já o autismo sindrômico ocorre em aproximadamente $25 \%$ dos casos, a causa genética ocorre em cerca de $75 \%$ dos casos e geralmente é monogênica (um único gene envolvido), o risco de ocorrência em irmãos é menor (4\% a 6\%) do que no autismo essencial, e a história familiar é menos frequente (9\%) (MANUAL, 2014; DELOBEL-AYOUB et al,2015; MITRA et al, 2016; TROMANS et al, 2018).

A deficiência intelectual ou retardo mental é caracterizada por atraso na aquisição de habilidades e aprendizagem, mas dificilmente as limitações apresentadas pelo indivíduo portador do transtorno serão completamente superadas com o tempo, mesmo com todo o esforço e tratamento disponível. Por isso o termo "retardo mental" é inadequado, pois traz consigo a ideia de que esse transtorno do desenvolvimento pode ser 
superado com o tempo. Indivíduos com deficiência intelectual apresentam déficits no desenvolvimento caracterizados por limitações no (a) funcionamento intelectual e no (b) comportamento adaptativo. $\mathrm{O}$ funcionamento intelectual, geralmente chamado de inteligência, inclui uma ampla gama de atividades mentais, como a capacidade de raciocínio lógico, inteligência prática (solução de problemas), capacidade de aprendizado, habilidades verbais e assim por diante. Em outras palavras, o funcionamento intelectual é definível como a capacidade global que permite ao indivíduo entender a realidade e interagir com ela. O comportamento adaptativo se expressa como competência em habilidades sociais, conceituais e práticas. As habilidades sociais incluem habilidades interpessoais, responsabilidade social, autoestima, resolução de problemas sociais, capacidade de seguir as regras da sociedade. As habilidades conceituais incluem a capacidade de entender tempo, finanças e idioma. As habilidades práticas incluem a capacidade de usar ferramentas, realizar atividades da vida diária e interagir com outras pessoas. Todas essas habilidades são aprendidas ao longo do desenvolvimento e realizadas em resposta a problemas comuns e tarefas simples, que obviamente se tornam mais complexas à medida que a idade aumenta. Fatores genéticos e ambientais podem contribuir para o desenvolvimento da deficiência intelectual, que afeta $3 \%$ da população, é 1,5 vezes mais frequente em homens que em mulheres e pode ser acompanhada de outros transtornos do desenvolvimento neural, como autismo, epilepsia e TDAH. Atrasos na linguagem ou nas habilidades motoras podem ser observados aos dois anos de idade, mas deficiências leves podem não ser reconhecidas até mesmo depois da infância. Aproximadamente 10 a $20 \%$ dos adultos com deficiência intelectual apresentam comportamentos desafiadores, incluindo agressão, comportamentos socialmente inadequados (como gritos, ofensas verbais, masturbação em público), automutilação e retração. Esses comportamentos podem ser duradouros e prejudiciais à qualidade de vida do indivíduo em questão, aumentando o risco de abuso, negligência, privação, institucionalização, contenção física e química, em comparação com indivíduos com deficiência intelectual sem comportamentos desafiadores. Além disso, comportamentos desafiadores podem afetar negativamente o ambiente imediato do indivíduo em questão, os cuidadores podem ser submetidos a abusos físicos e verbais, ou testemunhar comportamentos autolesivos, gerando ansiedade, raiva, medo e exaustão emocional nos cuidadores e familiares. As manifestações de deficiência intelectual geralmente são percebidas na infância ou adolescência (LEE; CACELLA; MARWAHA, 2021). 
A epilepsia é uma doença neurológica caracterizada por crises convulsivas recorrentes. Com relação à causa, as epilepsias podem ser de origem genética, infecciosa (como a síndrome de Zika congênita), metabólica, imunológica ou de causa desconhecida. Com base na prevalência, a epilepsia é classificada em epilepsias comuns e epilepsias raras. Fatores genéticos estão envolvidos em $70 \%$ da totalidade dos casos de epilepsia. As epilepsias raras respondem por 5\% dos casos de epilepsia e são encontradas em síndromes genéticas ou doenças genéticas raras, as quais são acompanhadas de outras características físicas internas e/ou internas, com ou sem alterações comportamentais, como em síndromes acompanhadas de transtornos do desenvolvimento neural. Em casos de epilepsias raras, o fator genético geralmente é uma característica que afeta um único gene (mutação única, ou causa monogênica). Já em casos de epilepsias comuns, diversas características genéticas podem atuar simultaneamente para a manifestação da epilepsia (causa poligênica) e em conjunto com fatores ambientais (não genéticos) (THAKRAN et $a l, 2020)$. Neste artigo, o tipo de epilepsia que interessa é a epilepsia que acompanha transtornos do desenvolvimento neural, ou seja, um tipo de epilepsia que faz parte de um quadro clínico que engloba outras manifestações (por isso chamado de síndrome), de causa genética ou não.

O transtorno de déficit de atenção e hiperatividade (TDAH) é um dos transtornos mais comuns na infância, afeta $7 \%$ das crianças e adolescentes e até $6 \%$ dos adultos em todo o mundo, pode ter consequências importantes, prejudicando interações sociais, aumentando a chance de fracasso escolar e laboral, e de envolvimento em comportamentos de risco (dependência de álcool e drogas, por exemplo). A incidência de TDAH é duas vezes maior em homens do que em mulheres, e o TDAH pode estar associado a outros transtornos do desenvolvimento neural, como o autismo e a deficiência intelectual. O TDAH pode se apresentar segundo três subtipos: predominantemente desatento (cerca de $20 \%$ dos casos); predominantemente hiperativo/impulsivo (cerca de $10 \%$ dos casos); tipo combinado, com manifestações de ambos (cerca de $70 \%$ dos casos). As principais manifestações de hiperatividade e impulsividade são: não conseguir ficar sentado quando necessário, estar sempre em movimento, falar excessivamente, dificuldade para esperar a sua vez, falta de paciência, deixa escapar respostas antes que se tenha terminado de fazer a pergunta. As principais manifestações de desatenção são: cometer erros por descuido, não conseguir manter a atenção no trabalho ou lazer, dificuldade para seguir instruções ou concluir os trabalhos, dificuldade para organizar 
tarefas e atividades, perder coisas necessárias para tarefas e atividades, distração com estímulos ou pensamentos não relacionados às tarefas, recorrência em esquecer atividades diárias ou compromissos. O TDAH está relacionado a uma variedade de fatores que incluem componentes genéticos e ambientais. Mas provavelmente a maior parte dos casos decorre de uma soma de várias características genéticas simultâneas (causa poligênica) (GNANAVEL et al, 2019; CABRAL; SOARES, 2020; MAGNUS et al, 2021).

Dislexia se refere ao transtorno de aprendizagem com deficiência na leitura e escrita, o que compromete a compreensão e interpretação de textos. As crianças com dislexia lutam para pronunciar palavras e reconhecer as palavras "à vista", e apesar da pouca fluência na leitura e dificuldades com a ortografia, elas não têm dificuldades com linguagens oral ou não verbal, e outras áreas do desenvolvimento cognitivo não são afetadas. A dislexia é dita "do desenvolvimento" para diferenciar de eventual dislexia decorrente de lesões cerebrais posteriores ao desenvolvimento do cérebro, como traumatismo craniano, acidente vascular cerebral ou tumor cerebral. Aproximadamente $7 \%$ da população tem dislexia, que pode acompanhar outros transtornos do desenvolvimento neural, como o TDAH (REMIEN; MARWAHA, 2021).

A discalculia é um transtorno com dificuldades, acima da média e persistentes, no aprendizado de habilidades relacionadas à matemática, e é uma causa importante de baixa autoestima, agravada quando a criança é insultada com termos como "burra", "retardada", "lesada" seja pela família, professores ou colegas. A frustração e baixa autoestima podem se manifestar como sentimentos internalizados (depressão e ansiedade) ou externalizados (agressividade e agitação). Existe um risco maior de outros transtornos do desenvolvimento neural em pessoas com discalculia, como dislexia (até $40 \%$ dos casos) e transtorno do déficit de atenção e hiperatividade (até $20 \%$ dos casos). A discalculia é uma causa importante de fracasso e evasão escolares, e na idade adulta está relacionada com aumento do risco de depressão e maior risco de desemprego. A discalculia é dita "do desenvolvimento" para diferenciar daquela eventualmente decorrente de alguma lesão cerebral posterior ao desenvolvimento do cérebro, como traumatismo cranioencefálico, acidente vascular cerebral ou tumor cerebral. Na discalculia do desenvolvimento, as dificuldades não são devidas a deficiência intelectual, deficiência sensorial, distúrbios mentais, outros transtornos neurológicos ou instrução inadequada. A discalculia do desenvolvimento afeta cerca de 3-7\% das crianças em idade escolar (HABERSTROH; SCHULTE-KÖRNE, 2019). 
A gagueira do desenvolvimento é um transtorno de fluência da fala normal e no padrão de tempo da fala, tem início na infância, é inapropriado para a idade do indivíduo e persiste por longo tempo. A gagueira geralmente começa de forma gradual, afetando palavras isoladas, mas se torna mais frequente e interfere nas frases completas à medida que o transtorno progride. A gagueira é dita gagueira do desenvolvimento para diferenciar da gagueira neurológica, decorrente de acidente vascular cerebral ou outras condições patológicas que acometem o cérebro. Estudos com gêmeos e famílias mostram que a genética está envolvida em muitos casos de gagueira, sendo responsável por 50 a $80 \%$ dos casos. O risco de gagueira é três vezes maior em pessoas com parentes biológicos de primeiro grau em comparação com a população em geral. A gagueira do desenvolvimento é caracterizada por um conjunto de manifestações involuntárias como repetição de parte de palavras, prolongamentos de fonemas, palavras quebradas, bloqueios silenciosos, circunlocuções, e excesso de tensão física. Movimentos como piscar os olhos, tiques, tremores, movimentos bruscos de cabeça, movimentos respiratórios, podem acompanhar a gagueira. A intensidade da gagueira pode variar de acordo com a situação e pode estar associada à antecipação temerosa da gagueira, que exacerba o problema. A ansiedade, $\mathrm{o}$ constrangimento, a insegurança, o estresse, a vergonha e o bullying resultantes podem causar limitações na participação social efetiva e nas realizações acadêmicas ou ocupacionais. A idade de início da gagueira do desenvolvimento varia de 2 a 7 anos, com 80 a $90 \%$ dos indivíduos afetados apresentando sintomas aos 6 anos de idade. A prevalência de gagueira do desenvolvimento é duas vezes maior no sexo masculino, e afeta aproximadamente $10 \%$ das crianças e $1 \%$ dos adultos. Até $65 \%$ das crianças têm resolução espontânea da gagueira, mas a intervenção precoce na infância aumenta a chance de resolução eficaz do problema, e para isso é interessante buscar auxílio de profissional fonoaudiólogo. A gagueira do desenvolvimento pode ser acompanhada de manifestações de outros transtornos do desenvolvimento neural, como autismo, TDAH, e paralisia cerebral (CHOO; SMITH; LI, 2020; MAGUIRE, et al, 2020)

A paralisia cerebral é um grupo de distúrbios permanentes que afetam o desenvolvimento do movimento e/ou cognição e afeta cerca de 2,5 a cada 1.000 nascidos vivos. Há uma ampla variedade de graus e tipos de comprometimento motor e da capacidade cognitiva. A paralisia cerebral pode ser acompanhada de outros transtornos do desenvolvimento, como epilepsia (45\% dos casos), deficiência intelectual (50\% dos casos), além de outras complicações como deformidades ortopédicas (principalmente nos 
pés, desvios de coluna e luxação de quadril; 30\%), dificuldades de alimentação, anomalias visuais, deficiência auditiva (20\%), dificuldade para articular a fala (50\%), dor (50\%), perda da visão (10\%), estrabismo (50\%), incontinência urinária ou bexiga neurogênica (50\%), déficit de crescimento, osteopenia (até 70\%, mais comum nos casos mais graves), distúrbios do sono, problemas com a dentição. O desenvolvimento anormal, ou lesão cerebral, que causa paralisia cerebral não é progressivo, ocorre num determinado momento, que pode ser nos períodos pré-natal (80\% dos casos), perinatal ou pós-natal. Portanto, uma história de regressão do desenvolvimento não é compatível com paralisia cerebral. As principais causas de paralisia cerebral são: malformações congênitas do cérebro; infecções no sistema nervoso central; AVC; anormalidades genéticas; diminuição da oxigenação cerebral/hipóxia; icterícia neonatal; acidentes e traumatismos cranioencefálicos. Vários fatores aumentam o risco de paralisia cerebral, tais como: prematuridade e baixo peso ao nascer, gravidez múltipla, problemas da placenta, hipoglicemia neonatal, aspiração de mecônio, pré-eclâmpsia, entre outros REMIEN; MARWAHA, 2021).

Esses dados mostram que, mesmo levando em conta que há superposição de diagnósticos, aproximadamente 20 a $25 \%$ da população mundial apresenta pelo menos algum transtorno do desenvolvimento neural, o que gera um custo econômico substancial (ARORA et al, 2018). Em um país com renda elevada, como a República da Coreia, o custo anual apenas com o TDAH chega a $0,004 \%$ do PIB (gross domestic product, GDP) (MINHA et al, 2020).

Como o TDAH afeta de 6 a 7\% da população, e os transtornos do desenvolvimento neural afetam pelo menos $20 \%$ da população, pode-se, então, extrapolar o custo anual de todos os transtornos do desenvolvimento neural, em países com renda elevada, para pelo menos cerca de 0,012\% do PIB. Entretanto, de acordo com Olusanya et al (2020) a maior parte das pessoas com transtornos do desenvolvimento vive em países com renda baixa ou média.

Com relação ao corpo caloso, em $70 \%$ dos casos a baixa inteligência está ligada à sua agenesia parcial e a convulsões em $50 \%$ dos casos. Os mesmos autores afirmam que parte dos portadores são assintomáticos vivendo normalmente. Apesar de poder ocorrer como um defeito isolado, a agenesia do corpo caloso, se apresenta frequentemente associada a outras anomalias como a holopresencefalia, que consiste na falta de 
segmentação da porção anterior do prosencéfalo. (MOORE; PERSAUD; TORSHIA, 2016)

Da mesma forma que essa esse fato descrito, More, Persaud e Torshia (2016) afirmam que o terceiro ventrículo pode estar aumentado se desenvolvendo acima do teto dos ventrículos laterais, que também estão aumentados em decorrência da ausência do corpo caloso.

\section{CONCLUSÃO}

Os transtornos do desenvolvimento neural representam um desafio para a medicina, educação especial, pessoas e famílias diretamente afetadas e para a sociedade, pois geram consequências emocionais, econômicas para os sistemas de saúde e educacional.

Embora os transtornos do desenvolvimento neural tenham causas e manifestações diversas, há um corpo de evidências, a cada dia mais sólido, que sinaliza para a existência de mecanismos celulares comuns a todos eles: o desequilíbrio entre a atividade do principal neurotransmissor excitatório, o glutamato, e o principal neurotransmissor inibitório, o GABA, com predomínio do primeiro; e a perturbação da neurogênese.

A grande complexidade microestrutural dos circuitos neuronais envolvidos funções e atividades desse sistema, permite imaginar o funcionamento do cérebro cognitivo, comportamental e social como uma nuvem plástica de vetores. Essa, resultante de milhões de vetores, com intensidades e direções (positivas ou negativas) das mais variadas e que oscilam em resposta aos diversos estímulos externos, que interagem com a bagagem de informações sobre as experiências vividas e atuam sobre uma base genética permissiva.

Uma abordagem cartesiana dos transtornos do desenvolvimento, onde para um transtorno exista uma droga específica e potente, com forte efeito terapêutico, pode parecer pouco factível. De fato, até o presente momento, os tratamentos testados para os transtornos do desenvolvimento, ou são ineficazes, ou não trazem resultado satisfatório para uma parte significativa dos pacientes, ou apresentam efeitos adversos importantes.

A existência de mecanismos celulares comuns a todos esses transtornos permite eleger uma estratégia de tratamento que, quiçá, poderia ser aplicada no tratamento de diferentes transtornos do desenvolvimento. 
É bastante razoável, de acordo com a farmacologia, que é remota a probabilidade de uma única substância atuar simultaneamente em vários tipos e subtipos de receptores de glutamato e de GABA, de modo a restaurar o desequilíbrio instituído nos complexos circuitos em que eles estão envolvidos.

É mais plausível que um conjunto de substâncias usadas simultaneamente alcance esse efeito e nesse sentido, jogar sobre essa nuvem plástica de um conjunto de substâncias que atuem de modo discreto sobre diversos receptores de GABA e de glutamato, e através de mecanismos diversos, talvez seja uma possibilidade viável e melhor tolerada, embora ainda não experimentada.

Esses conhecimentos passam a ser requisitos suporte para profissionais envolvidos na educação especial contribuindo para melhor compreensão do processo ensino e aprendizagem para portadores de necessidades especiais.

\section{REFERÊNCIAS}

ARORA, Narendra K. et al. Neurodevelopmental disorders in children aged 2-9 years: Population-based burden estimates across five regions in India. PLoS Med., v. 15, n.. 7, e1002615, Jul, 2018. PMID: 30040859. DOI: 10.1371/journal.pmed.1002615.

CABRAL, Maria Demma I.; LIU, Stephanie; SOARES, Neelkamal. Attentiondeficit/hyperactivity disorder: diagnostic criteria, epidemiology, risk factors and evaluation in youth. Transl Pediatr. v. 9, sup. 1, S104-S113, 2020. PMID: 32206588. DOI: $10.21037 /$ tp.2019.09.08.

CHOO, Ai Leen; SMITH, Sara Ashley; LI, Hongli. Associations between stuttering, comorbid conditions and executive function in children: a population-based study. BMC Psychol. v. 8, n. 1, p. 113, Oct, 2020. PMID: 33129350. DOI: 10.1186/s40359020-00481-7.

DELOBEL-AYOUB, Malika et al. Socioeconomic disparities and prevalence of autism spectrum disorders and Intellectual disability. PLoS One. v. 10, n. 11, e0141964, Nov, 2015. PMID: 26540408. DOI: 10.1371/journal.pone.0141964.

GILBERT, J.; HY, Main. Fundamental elements in autism: from neurogenesis and neurite growth to synaptic plasticity. Front Cell Neurosci. v. 11, n. 359, Nov, 2017. PMID: 29209173. DOI: 10.3389/fncel.2017.00359.

GNANAVEL, Sundar, et al. Attention deficit hyperactivity disorder and comorbidity: a review of literature. World J Clin Cases. v. 7, n. 17, p. 2420-2426, Sep, 2019. PMID: 31559278. DOI: 10.12998/wjcc.v7.i17.2420. 
HABERSTROH, Stefan; SCHULTE-KÖRNE, Gerd. The diagnosis and treatment of dyscalculia. Dtsch Arztebl Int. v. 116, n. 7, p. 107-114, Feb, 2019. PMID: 30905334. DOI: 10.3238/arztebl.2019.0107.

HALLMAN-COOPER, Jamika L.; CABERO, Franklyn Rocha. Cerebral Palsy. StatPearls Publishing, Apr, 2021. PMID: 32491600.

HEUER, Katja; TORO, Roberto. Role of mechanical morphogenesis in the development and evolution of the neocortex. Phys Life Rev. Dec, p. 233-239, 2019. PMID: 30738760. DOI: 10.1016/j.plrev.2019.01.012.

JACKMAN, Skyler L.; REGEHR, Wade G. The mechanisms and functions of synaptic facilitation. Neuron. v. 94, n. 3, p. 447-464, May, 2017. PMID: 28472650. DOI: 10.1016/j.neuron.2017.02.047.

LEE, Keun; CACELLA, Marco; MARWAHA, Raman. Intellectual disability. StatPearls Publishing, Jan, 2021. PMID: 31613434.

MAGNUS, Warren et al. Attention deficit hyperactivity disorder. StatPearls Publishing, May, 2021. PMID: 28722868.

MAGUIRE, Gerald, A. et al. The pharmacologic treatment of stuttering and its neuropharmacologic basis. Front Neurosci. v. 14, n. 158, Mar, 2020. PMID: 32292321. DOI: $10.3389 /$ fnins.2020.00158.

MANUAL diagnóstico e estatístico de transtornos mentais [recurso eletrônico] : DSM5 / [American Psychiatric Association; tradução de Maria Inês Corrêa Nascimento ... et al.]; revisão técnica: Aristides Volpato Cordioli ... [et al.]. - 5. ed. - Dados eletrônicos. - Porto Alegre : Artmed, 2014. Disponível em: http://www.niip.com.br/wpcontent/uploads/2018/06/Manual-Diagnosico-e-Estatistico-de-Transtornos-MentaisDSM-5-1-pdf.pdf. Acesso em 29 ago. 2021.

MARTÍNEZ-CERDEÑO, Verónica. Dendrite and spine modifications in autism and related neurodevelopmental disorders in patients and animal models. Dev Neurobiol. v. 77, n. 4, p. 393-404, Apr, 2017. PMID: 27390186. DOI: 10.1002/dneu.22417.

MINHA, Hong et al. Economic burden and disability-adjusted life years (DALYs) of attention deficit/hyperactivity disorder. J Atten Disord v. 24, n. 6, p. 823-829, Apr, 2020. PMID: 31364445 DOI:10.1177/1087054719864632.

MITRA, Ileena et al. Pleiotropic mechanisms indicated for sex differences in autism. PLoS Genet. v. 12, n. 11, e1006425, Nov, 2016. PMID: 27846226. DOI: 10.1371/journal.pgen.1006425.

MOORE, Keith L; PERSAUDE, T. V. N; TORCHIA, Mark G. Embriologia clínica. edição PIN Rio de janeiro: GEN Guanabara Koogan, 2016, 552 p. ISBN-10: 8535283838. ISBN-13: 978-8535283839.

NIFTULLAYEV, Sadig; LAMARCHE-VANE, Nathalie. Regulators of Rho GTPases in the nervous system: mMolecular implication in axon guidance and neurological 
disorders. Int J Mol Sci. v. 20, n. 6, p 1497, Mar, 2019. PMID: 30934641. DOI: 10.3390/ijms20061497.

LUSANYA Bolajoko O. et al. Global burden of childhood epilepsy, intellectual disability, and sensory iImpairments. Pediatrics, v. 146, n. 1, e20192623, Jul, 2020. PMID: 32554521. DOI: 10.1542/peds.2019-2623.

PAN, Yi-Hsuan; WU, Nan; YUAN, Xiao-Bing. Toward a better understanding of neuronal migration deficits in autism spectrum disorders. Front Cell Dev Biol. v. 7, n. 205, Sep. 2019. PMID: 31620440. DOI: 10.3389/fcell.2019.00205.

REMIEN, Kailey; MARWAHA, Raman. Dyslexia. StatPearls Publishing, May, 2021. PMID: 32491600.

THAKRAN Sarita, et al. Genetic landscape of common epilepsies: advancing towards precision in treatment. Int J Mol Sci. v. 21, n. 20, p. 7784, Oct, 2020.

PMID: 33096746. DOI: 10.3390/ijms21207784.

TROMANS, Samuel et al. The prevalence of autism spectrum disorders in adult psychiatric inpatients: a systematic review. Clin Pract Epidemiol Ment Health. 2018 Aug v. 29, n. 14, p.177-187, Aug, 2018. PMID: 30197663. DOI: $10.2174 / 1745017901814010177$. 